\title{
Relationship of Food Craving Behavior with Body Mass Index and Body Composition in Reproductive Age Females
}

\author{
María-De-Los-Remedios Moreno-Frías ${ }^{1}$, Sonya Chaudhari ${ }^{2}$, María-Raquel Huerta-Franco ${ }^{1,2^{*}}$ \\ ${ }^{1}$ Department of Applied Sciences to Work, Division of Health Sciences, Campus Leon, University of Guanajuato, Leon, Mexico \\ ${ }^{2}$ Department of Biomedical and Health Informatics, University of Missouri-Kansas City School of Medicine, Kansas City, \\ Missouri, USA \\ Email:mdlr.morenofrias@ugto.mx, sc5y7@mail.umkc.edu, *m rhuertafranco@ugto.mx
}

How to cite this paper: Moreno-Frias, M.R., Chaudhari, S. and Huerta-Franco, M.-R. (2017) Relationship of Food Craving Behavior with Body Mass Index and Body Composition in Reproductive Age Females. Food and $\mathrm{Nu}$ trition Sciences, 8, 699-713.

https://doi.org/10.4236/fns.2017.87049

Received: June 7, 2017

Accepted: July 8, 2017

Published: July 11, 2017

Copyright $\odot 2017$ by authors and Scientific Research Publishing Inc. This work is licensed under the Creative Commons Attribution International License (CC BY 4.0). http://creativecommons.org/licenses/by/4.0/

\section{Open Access}

\begin{abstract}
Objective: To estimate the relationship of Food Craving (FC) behavior with females' Body Mass Index (BMI), and body-composition. Design, setting and participants: A cross-sectional study of 302 reproductive-age women from middle-socioeconomic class was conducted at the Health \& OccupationalEnvironmental Laboratory. Variable Measures: A FC behavior questionnaire (FCQ) was designed and validated in 151 female subjects. This questionnaire evaluated five dimensions: FC-leisure, FC-psychological reactance, FC-depression, FC-anxiety/stress, and FC-anger. Dependent variables were Body Mass Index $\left(\mathrm{BMI}, \mathrm{kg} / \mathrm{m}^{2}\right)$ and the body fat mass. Interventions: A second group of 151 women completed the FCQ. Anthropometrical variables were recorded using the International Society for the Advancement of Kinanthropometry procedure. Analysis: A multiple regression-analysis using STATISTICS version 7 was performed to determine the relationship of FC behavior with anthropometrical variables described. Results: We demonstrated that 98.7\% of women had FC behavior. Women with higher BMI had higher scores of FC-depressions $(\mathrm{p}=0.02)$ and FC-anger $(\mathrm{p}=0.007)$. Food craving behavior $(\mathrm{p}<0.0008)$, and food psychological-reactance $(\mathrm{p}=0.006)$, were positive predictors of BMI; food psychological reactance was also a positive predictor of upper and lower-body fat mass $(p=0.005)$ and $(p=0.008)$, respectively. Conclusion and Implications: The food craving behavior is a common problem in the female population. Food psychological reactance, in addition to another affective alteration that present the population of women are predictor variables for the increase in BMI and in body-fat mass. It is important that health professionals are aware of the affective states of their patients.
\end{abstract}




\section{Keywords}

Food Craving Behavior, Body Mass Index, Body Composition, Reproductive Age Females

\section{Introduction}

Food Craving (FC) or "foodcraving" is a motivational state that promotes ingestive behaviors [1]. It is often described as an irresistible urge to eat food, differing from the normal physiological sensation of hunger. FC is triggered by certain emotional states, such as psychological and physical stress, anxiety, depression, anger, or psychological reactance to food [2] [3] [4] [5].

This research was based on the cognitive theory of Vecina [6]. This theory defines the emotions as adaptive trends associated with physiological manifestations, subjective experiences, and information processing prior to an event. Psychological-emotions are generated from the limbic system, the cortex, and neocortex. A person seeks to generate positive emotions (contentment, satisfaction, pride, hope and peace) and avoid negative emotions (sadness, anger, anxiety, boredom, irritability, grief fear and anger) [6].

Food craving behavior (FCB) is manifested as a positive emotion. This can lead to repetitive food intake leading to obesity and counterproductive emotional states.

The prevalence of FCB reported from previous studies varies worldwide [2] [7] [8] [9] [10] [11]. Results range from $28 \%$ to $97 \%$ [9] [10] [11]. This phenomenon is found more frequently in female subjects allowing researchers to generate hypotheses from a biological approach related to psycho-endocrinology. For example, changes in eating behaviors during the menstrual cycle and states of mood variations are more frequently reported in female subjects [2]-[11]. However, there are limited studies evaluating FCB in females. The cause has not been fully defined. One limitation is from lack of valid and sensitive instruments to measure the FC variable [12] [13] [14] [15] [16]. Therefore, we hypothesized that the frequency of FCB is high and this is between FCB and females' affective states, body fat, and BMI. The aims of our study were: 1) to develop and validate a questionnaire to measure FCB in females; 2) to estimate the relationship of FCB with females' affective-states, Body Mass Index (BMI), body-composition, and 3) to determine the differences in the score of the FC behavior in females during the menstrual cycle, and with the practice of physical exercise.

\section{Methodology}

\subsection{Ethical and Legal Consideration}

This study was approved by the Ethics Committee of the Division of Science and Engineering from the Campus Leon of the University of Guanajuato. The study 
was considered minimal risk. It complied with the rules for conducting clinical research in human subjects established by the Secretary of Health of Mexico and the Declaration of Helsinki [17].

\subsection{Subjects}

Subjects eligible to participate in this study included: 1) reproductive age women between age 18 - 40 years; 2) residents of urban areas of the city; 3) those who had adequate level of schooling to read, understand, and answer the FCQ; 4) normal frequency of menstrual cycle ( $\geq 21$ and $<35$ days); 5) without physical-anatomical alterations; 6) nor use any drugs for weight control or for mood alterations such as anxiolytics or antidepressants [18]. Women with any psychopathology that affected the study variable (FCB), such as anorexia, bulimia nervosa or other eating disorders, diabetes, polycystic ovary syndrome, hypothyroidism, delayed adrenal hyperplasia, Cushing's syndrome, Addison's syndrome, insulin resistance or metabolic syndrome were excluded. Participants were evaluated from August 2012 to August 2014.

\subsection{Sample Size and Procedure to Select the Subjects}

The sample size was calculated with the EPIDAT 3.1 software

(http://dxsp.sergas.es). The parameters considered were size of the population of reproductive age women from our city $(655,861$ habitants), and expected proportion of individuals with FCB of $90 \%$, with an absolute accuracy of 5\%, according to the international literature [9] [10] [11]. With these parameters a sample size of 139 subjects was calculated. We considered 151 female subjects as a sample size for this study.

\subsection{Validity and Reliability of Food Craving Questionnaire (FCQ)}

The FCQ was validated in 151 subjects. Participants were of middle socioeconomic class and residents of the urban areas [19]. To validate the FCQ, we used the technique of natural semantic networks (NSN) [20]. This technique highlights the importance of measuring the psychological significance in the construction of a questionnaire. In our study, subjects were required to perform the following two fundamental tasks: 1) define with clarity and precision the stimulus presented to them using a minimum of five single words that related to FCB; 2) read their defining word and assign numbers based on the importance of proximity or considered for encouragement. From this, we identified the psychological concept of FCB for the study population and the main situations it occurs. We developed a test plan consisting of the theoretical basis of the study variable (FCB). Once, we have the conceptual definition of FCB variable, we identify, and conceptualized the factors (dimensions), which make up the variable (FCB), which were: anxiety, stress, depression, leisure, food psychological reactance, and anger. Each factor had a requirement for a minimum of "five" questions (items). 


\subsection{Standardization of Food Craving Questionnaire (Analysis of the Items)}

To standardize the FCQ, we proceeded to evaluate: a) Distribution: 36 items had positive bias (>0.5): items $1-3,5-35$, and 37. Item 36 exhibited negative bias $(<0.5)$. Four of the items presented a normal distribution; b) directionality: items 1 and 7 had a flattened frequency indicating that the remaining items were consistent with the theory; c) discrimination: A Student's t-test was performed for independent samples. The items were statistically significant $(p<0.05)$ and no items were discarded; d) internal consistency: to determine that the items were consistent with each other a Cronbach $\alpha$ analysis was performed. The correlation of the total corrected element from each of them was greater than 0.2 which indicated all items were consistent with each other $(\alpha=0.92)$.

\subsection{Validity of the Food Craving Questionnaire}

The validity of the FCQ was determined using a factorial statistical analysis. Six items were removed because they presented with values less than 0.4 in the matrix of rotated components (items 1, 7, of leisure; item 18 of anxiety; items 21 and 25 of depression; and item 26 of anger, as defined in test plan described previously). The results of the factor analysis showed six factors in the matrix of rotated components, orthogonal rotation method. Rotation converged in 9 iterations. A factor was removed because not present the appropriate values for the rotated component matrix $(<0.4)$, giving a total solution of 5 factors and 30 items, as well as the total of items for each factor. Subsequently, the total variance explained in each of the factors in the FCQ using the extraction method of principal component analysis, where it was observed that the five factors explain $63.5 \%$ of the phenomenon anxiety described by the food. The reliability of the instrument was determined by Cronbach $\alpha$ statistical analysis for the remaining 30 items. A value of $\alpha=0.92$ for total test which indicated there were high levels of reliability.

\subsection{Procedures}

Once the study was approved by the Ethics Committee (described above), volunteers gave their consent to participate in the study. Participants answer questions related to the clinical history: age, occupation, place of residence, schooling level, civil status, income, gynecological data (age at menarche, characteristics of the menstrual cycle, use of oral contraceptives, and number of pregnancies, abortions, and cesarean sections). We also asked questions about practice of physical exercise (type of physical exercise, time since practice, number of days per week of practice, and duration in minutes), following the criteria of the American College of Sports Medicine [21]. Subsequently, the participants answered the FC behavior questionnaire described above.

\subsection{Anthropometrical Evaluation}

The anthropometrical measurements followed guidelines according to the In- 
ternational Standard for the Anthropometrical Assessment of the International Society for the Advancement of Kinanthropometry (ISAK) [22]. We measured the weight, height, and skin-fold thickness of triceps, thigh and supra-iliac. The measurement of height was determined with a stadiometer brand SECA with a precision of $1 \mathrm{~mm}$. The evaluation of the body fat mass (BF) was determined by two methods: a) through skin-fold technique [percentage (\%) BF-SK)] using a caliper Harpenden ${ }^{\oplus}$ with a precision of $0.2 \mathrm{~mm}$ and $0.20 \mathrm{~mm}$ graduation; and b) $\mathrm{BF}$ determined by bioelectrical impedance analysis (\% BF-BI) by Omron ${ }^{\circledR}$ Scales HBF-400 (Omron Healthcare CO., LTD. Japan). Lean body mass (LBM) or mass free of fat was then estimated using the difference of body weight and the percentage of BF [23]. For this study, the BMI was considered to define the criteria of low weight $\left(<18.5, \mathrm{~kg} / \mathrm{m}^{2}\right)$, normal weight $\left(18.5\right.$ to $\left.29.9, \mathrm{~kg} / \mathrm{m}^{2}\right)$; overweight (25 to $\left.29.9, \mathrm{~kg} / \mathrm{m}^{2}\right)$; obese class I ( 30 to $\left.34.9 \mathrm{~kg} / \mathrm{m}^{2}\right)$, obese class II $(35-39.9, \mathrm{~kg}$ $\left./ \mathrm{m}^{2}\right)$, morbidly obese $\left(>40, \mathrm{~kg} / \mathrm{m}^{2}\right)[24]$.

\subsection{Statistical Analysis}

The data was analyzed with the STATISTICS version 7.0 (Stat-Soft, Inc. Tulsa OK), and SPSS software version 13 (Chicago, IL), was used to perform FCQ validation tests. The normal distributions of all quantitative variables were determined by the Shapiro-Wilks test. The anthropometrical, age of the women, and the age of menarche variables, follow normal distribution. Variables without normal distribution were analyzed with Kruskal-Wallis to compare the FC behavior in subjects grouped by BMI (underweight, normal weight, overweight and obese) [24]. Mann-Whitney U statistical test was used to compare median values of FC behavior of subjects which stratify by follicular or luteal phases of the menstrual cycle.

A forward step wise multiple regression analysis was performed, using as dependent variables, the anthropometrical data above mentioned, as independent variables, the FC behavior score and all FC dimensions (FC-anxiety-stress, FCdepression, FC-leisure, FC-psychological-reactance and FC-anger).

\subsection{Maximum Rating and Intensity of the Food Craving Behavior by Dimensions' Components}

For this study, we define a total score of FC behavior $=120$ Maximum rating, considering a low scores from 31 - 60 points, moderate, from 61 - 90, and for severe FC behavior from $91-120$ points respectively. For leisure maximum scores was 12 points, for low $(7-12)$, moderate (13 - 18) and severe (19 - 24) points, respectively. For anxiety/stress dimension, the maximum score was 40 points, being for low score of (11 - 20), for moderate (21 - 30) and for severe (31 - 40). For depression dimension, the maximum score was 12 points, being for low (4 - 6), for moderate (7 - 9) and for severe (10 - 12) points respectively. Anger dimension's maximum scores was 24 points, being for low $(7-12)$, for moderate $(13-18)$ and for severe $(19$ - 24) points, respectively. The maximum score of food psychological-reactance was 20 points, being for low (6 - 10), for mod- 
erate (11 - 15), and for severe (16 - 20) points, respectively. A Chi-squared test was performed to determine the association between the FC behaviors, frequencies among females' BMI category. In all cases, a p-value of $\leq 0.05$ was considered statistically significant.

\section{Results}

\subsection{General Characteristics of the Women}

The average age of the participants was $23.0 \pm 6.8$ years; they had an average schooling level of $13.3 \pm 3.0$ years. The distribution of the occupation of the volunteers demonstrated that 10 (6.6\%) make home activities, 7 (4.6\%) were employees, $17(11.3 \%)$ had a professional career, 115 (76.2\%) were students; one woman $(0.7 \%)$ was merchant, and other activities just one woman $(0.7 \%)$. In relation to the civil status, 131 (86.8\%) of the sample reported marital status was single and $18(11.9 \%)$ were married, divorced and free union were $2(1.4 \%)$ respectively. The socioeconomic level measured through Bronfman method indicates that $96.7 \%$ of participants belonged to the middle socioeconomic class [19].

The results of the anthropometrical and body-composition variables are shown in Table 1 . In this study, we demonstrate that 7 (4.7\%), were low body weight; $89(59.3 \%)$ of the subjects were normal weight, 44 (29.3\%) were overweight, and $10(6.7 \%)$, were obese grade I. Nevertheless, Table 1, shows the women's average body-fat mass was above the normal ranges (\% BF-BI $=29.6 \pm$ 7.6 , and $\%$ BF-SK $=41.0 \pm 20$ ), respectively.

Table 1. Show the mean and standard deviation (SD) of the anthropometrical variables of 151 women evaluated.

\begin{tabular}{cc}
\hline Variables & $\mathrm{X} \pm \mathrm{SD}$ \\
\hline Age (years) & $23.0 \pm 6.8$ \\
Weight $(\mathrm{kg})$ & $61.5 \pm 11.4$ \\
Heigh $(\mathrm{cm})$ & $160.4 \pm 6.1$ \\
BMI $\left(\mathrm{kg} / \mathrm{m}^{2}\right)$ & $23.8 \pm 3.8$ \\
Tricipital skinfold (mm) & $21.0 \pm 6.8$ \\
Sub-Scapular skinfold (mm) & $23.4 \pm 12.3$ \\
Thight skinfold (mm) & $33.4 \pm 13.1$ \\
Waist girth (cm) & $75.2 \pm 8.8$ \\
Abdomen girth (cm) & $85.4 \pm 9.4$ \\
Hip girth (cm) & $98.7 \pm 7.7$ \\
Arm girth (cm) & $28.2 \pm 6.8$ \\
\% BF-BI & $29.6 \pm 6.6$ \\
\% BF-UB & $27.1 \pm 6.4$ \\
\% BF-LB & $32.1 \pm 7.6$ \\
\% BF-SK & $41.0 \pm 20$ \\
\% LBM & $70.41 \pm 6.65$ \\
\hline
\end{tabular}

$\%$ BF-BI = percent of body fat, determined with bioelectrical impedance technique (mean value of upper and lower body); \% BF-UB = percentage of body fat mass by bioelectrical impedance technique of upper body; \% BF-LB = percentage of body fat mass by bioelectrical impedance technique lower body; \% BF-SK = percentage of body fat mass by skin-fold thickness; \% LBM = percentage of lean body mass (fat free mass). 


\subsection{Food Craving, Menstrual Cycle and Physical Exercise}

The average age at menarche was $12.2 \pm 1.4$ years; and 127 volunteers $(84.1 \%)$ had a length of the menstrual cycle of $\geq 21$ to 28 days, and $24(15.8 \%) \geq 28$ to 35 days, respectively. At time of interview, $52.8 \%$ of the volunteers were at follicular phase and $47.2 \%$ were in the luteal phase of the menstrual cycle. In this study, we did not find statistical differences when we compare the median scores of FC behavior between females at the follicular and those at luteal phase of the menstrual cycle (Mann-Whitney U tests $=$ Z-0.09, $\mathrm{p}>0.05$ ).

In this investigation, we found that $72 \%$ of subjects reported practice physical exercise (PE) frequency of $3.5 \pm 1.4$ days of week lasting $78.8 \pm 46.5$ minutes per day; 74 females (69\%) practice moderate- intensity PE, for 19 (18\%) was intense, and for 15 (14\%), was low-intensity. The results of Mann Whitney U test showed no significant difference in the median level of FC behavior among women who were in regular physical exercise in comparison with females were not practicing regular exercise $(Z=-0.43, \mathrm{p}=0.7)$.

\subsection{Frequency of Food Craving Behavior}

One hundred forty-eight (99\%) of females had FC behavior; 126 (83\%) were low-degree FC behavior, 22 (14.6\%) were moderate, and only one women $(0.7 \%)$ had severe FC behavior. The main trigger factor of the FC behavior was the leisure in $96 \%$ of participants in the study; following by food psychological reactance $(89 \%)$, depression (82\%), anxiety/stress (80\%) and anger (13\%), respectively.

Table 2 presents the frequency of FC behavior of women stratified by their $\mathrm{BMI}$, showed that normal weight, overweight, and obese females had prevalence of $59 \%, 29 \%$, and $7 \%$, of FC behavior, respectively (Pearson chi-square $=10.56$, $\mathrm{p}=0.01$ ). However, $85 \%$ of women had a score indicative of mild intensity FC behavior and $54 \%$ of them were normal weight.

Table 3 shows the results of the median (minimum and maximum) values and Kruskal-Wallis test, demonstrating that there were statistical differences of FC behavior among females with normal weight, overweight and obese $(\mathrm{H}$ of $\mathrm{K}-\mathrm{W}=10.05, \mathrm{p}=0.01$ ), being higher in those women with higher BMI. Women with higher BMI, also had higher scores of FC-depression ( $\mathrm{p}=0.02), \mathrm{FC}$-anger $(\mathrm{p}=0.007)$, and FC-psychological reactance $(\mathrm{p}=0.008)$.

Table 2. Frequency of Food craving behavior of women grouped by BMI $\left(\mathrm{kg} / \mathrm{m}^{2}\right)$, Pearson chi-square $=10.6, \mathrm{p}=0.01$.

\begin{tabular}{cccccc}
\hline & Under-W & Normal-W & Over-W & Obese I & Total \\
\hline FCB & $\mathrm{n}(\%)$ & $\mathrm{n}(\%)$ & $\mathrm{n}(\%)$ & $\mathrm{n}(\%)$ & $\mathrm{n}(\%)$ \\
Yes & $6(4.00)$ & $89(59.3)$ & $43(28.7)$ & $10(6.7)$ & $148(98.7)$ \\
No & $1(0.67)$ & $0(0.00)$ & $1(0.7)$ & $0(0.0)$ & $2(1.3)$ \\
Total & $7(4.7)$ & $89(59.3)$ & $44(29.3)$ & $10(6.7)$ & $150(100)$ \\
\hline
\end{tabular}

Under-W-underweight; Normal-W-normal weight; Over-W-overweight; Obese I = obese class I (30 to $\left.34.9 \mathrm{~kg} / \mathrm{m}^{2}\right) ; \mathrm{FCB}=$ Food craving behavior. 
Table 3. Shows the results of median (minimum-maximum) values and Kruskal-Wallis test, of the food craving behavior and its dimensions evaluated.

\begin{tabular}{cccccccc}
\hline & $\begin{array}{c}\text { Under-W } \\
\text { Median } \\
(\min -m a x) \\
\mathrm{n}=7\end{array}$ & $\begin{array}{c}\text { Normal-W } \\
\text { Median } \\
(\min -\max ) \\
\mathrm{n}=89\end{array}$ & $\begin{array}{c}\text { Over-W } \\
\text { Median } \\
(\min -\max ) \\
\mathrm{n}=44\end{array}$ & $\begin{array}{c}\text { Obese I } \\
\text { Median } \\
(\min -\max ) \\
\mathrm{n}=10\end{array}$ & $\begin{array}{c}\text { (min-max }) \\
\text { Rating }\end{array}$ & H-KW & P \\
\hline FCB & $40(30-56)$ & $45(31-118)$ & $50.5(30-84)$ & $53(33-87)$ & $(31-120)$ & 10.05 & $=0.01$ \\
Lesiure & $8(5-10)$ & $9(5-20)$ & $9.5(5-15)$ & $9.5(6-17)$ & $(7-24)$ & 3.77 & $\mathrm{~ns}$ \\
$\begin{array}{c}\text { Anxie- } \\
\text { ty/stress }\end{array}$ & $11(10-27)$ & $14(9-40)$ & $15(10-34)$ & $16.5(10-30)$ & $(11-40)$ & 6.9 & $\mathrm{~ns}$ \\
$\begin{array}{c}\text { Depression } \\
\text { Anger }\end{array}$ & $5(4-6)$ & $5(4-16)$ & $6(4-15)$ & $7(5-12)$ & $(4-12)$ & 9.53 & $=0.02$ \\
FPR & $6(6-6)$ & $6(6-24)$ & $6(6-14)$ & $6.5(6-12)$ & $(7-24)$ & 12.02 & $=0.007$ \\
\hline
\end{tabular}

Under- $\mathrm{W}$ = underweight; Normal-W = normal weight; Over-W = overweight; Obese I = obese class I; FCB = food craving behavior; FPR $=$ food psychological reactance; $\mathrm{H}-\mathrm{KW}=\mathrm{H}$ of Kruskal-Wallis statistical test; ns = non-significant.

The step-wise multiple regression analysis taking as dependent variable the FC behavior showed significant predictors for FC behavior were: the fat mass determined by bioelectrical impedance technique (\% BF-BI) of the upper- and lower body; fat mass assessed with skinfold technique (\% BF-SK); and the BMI, which were associated positively and significantly with FC behavior (Figures 1-4). The results of multiple regression tests enable us to predict with $95 \%$ of probability that a woman from the general population with the characteristics of the study sample and higher BMI and body fat mass will have a higher score of FC behavior.

Table 4 shows that food craving behavior; food psychological-reactance and anger were significant predictors of BMI and body fat mass. It is noteworthy that women, who present a higher score in food psychological reactance, have a significantly higher body fat mass and higher BMI.

\section{Discussion}

\subsection{Frequency of Food Craving Behavior}

In the present study, we validate a questionnaire of FC behavior in 151 reproductive age female subjects. There are limited studies done regarding FC behavior in Latin America. In Spanish-speaking populations, the term "food craving" is not well known. We defined FC behavior in our population as "the desire women have to consume food without having the emergence of hunger." From this definition, we designed and validated the FCQ.

The results of this investigation indicated the prevalence of FC behavior in this sample of reproductive age female subjects were high (99\%). Mild, moderate, and severe FC behavior prevalence were $85 \%, 15 \%$, and $0.7 \%$ respectively. There is controversy regarding the prevalence of FC behavior in various reports of international literature due to the lexicalization of the concept in terms of translation and adaptation of the term in different cultures. It becomes difficult to unify 


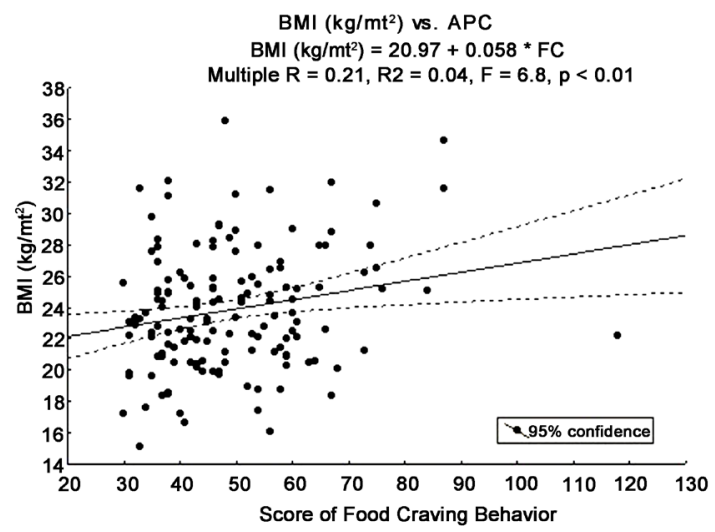

Figure 1. Shows a positive relationship among the women's Body Mass Index (BMI) with the score of food craving behavior (FCB). Demonstrated that women with higher BMI have higher scores of FCB.

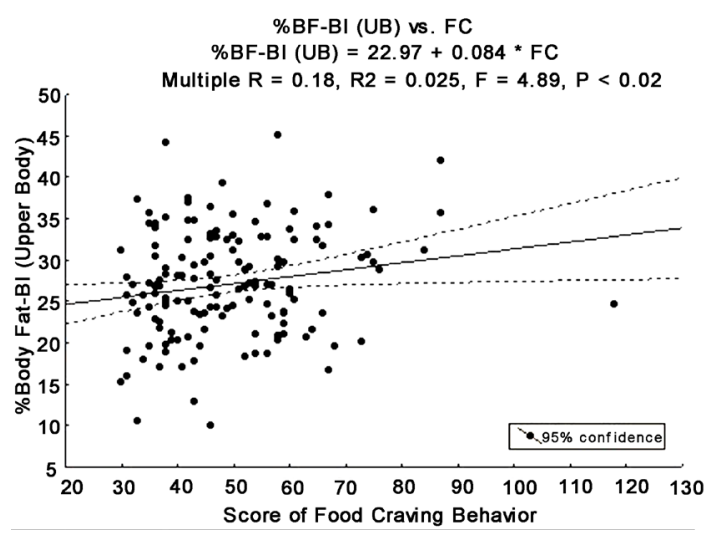

Figure 2. Shows a relationship among the body fat mass of the upper body determined by bioelectrical impedance [\% BF-BI (Upper Body)] with the score of food craving behavior (FCB). Demonstrated that women with higher body fat have higher scores of FCB.

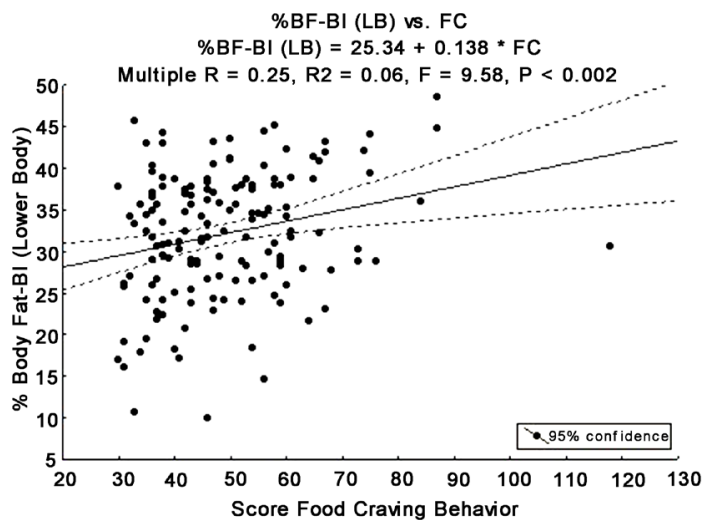

Figure 3. Shows a positive relationship among the body fat mass of the lower body, determined by bioelectrical impedance technique [\% BF-BI (Lower Body)] with the score of food craving behavior (FCB). Demonstrated that women with higher body fat have higher scores of FCB. 


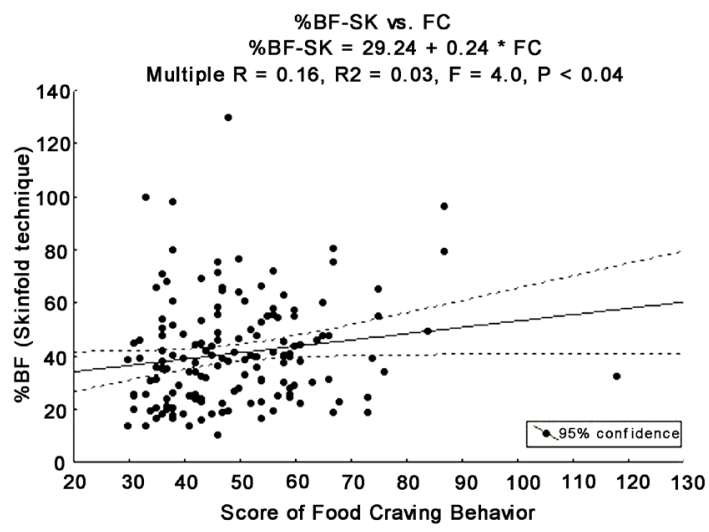

Figure 4. Shows a positive relationship between the body fat mass (percentage of body fat by skinfold technique) with the score of food craving behavior (FCB). Demonstrated that women with higher body fat have higher scores of FCB.

Table 4. Shows the results of multiple regression analysis taking as dependent variables the BMI and the body fat mass.

\begin{tabular}{|c|c|c|c|c|c|c|}
\hline \multicolumn{7}{|c|}{ Dependent variable \% BF-BI (UB), $\mathrm{R}=0.23, \mathrm{R}^{2}=0.05, \mathrm{~F}(1,15)=8.17, \mathrm{p}<0.005$} \\
\hline & Beta & SE & $B$ & SE & $t(148)$ & p-level \\
\hline Intercept & & & 23.52 & 1.34 & 18.00 & $=0.000$ \\
\hline Food psychological reactance & 0.23 & 0.08 & 0.35 & 0.12 & 2.86 & $=0.005$ \\
\hline \multicolumn{7}{|c|}{ Dependent variable \% BF-BI (LB), $\mathrm{R}=0.34, \mathrm{R}^{2}=0.12, \mathrm{~F}(2,15)=9.97, \mathrm{p}<0.00009$} \\
\hline & Beta & SE & $B$ & SE & $\mathrm{t}(147)$ & p-level \\
\hline Intercept & & & 23.50 & 2.05 & 11.47 & $=0.00$ \\
\hline Food psychological reactance & 0.22 & 0.08 & 0.40 & 0.15 & 2.69 & $=0.008$ \\
\hline Anger & 0.19 & 0.083 & 0.63 & 0.27 & 2.34 & $=0.021$ \\
\hline \multicolumn{7}{|c|}{ Dependent variable BMI $\left(\mathrm{kg} / \mathrm{m}^{2}\right), \mathrm{R}=0.27, \mathrm{R}^{2}=0.07, \mathrm{~F}(1,15)=11.71, \mathrm{p}<0.0008$} \\
\hline & Beta & SE & $B$ & SE & $\mathrm{t}(148)$ & p-level \\
\hline Intercept & & & 1.71 & 0.20 & 8.45 & $<0.0001$ \\
\hline Food Craving Behavior & 0.27 & 0.079 & 0.014 & 0.004 & 3.42 & $<0.0008$ \\
\hline \multicolumn{7}{|c|}{ Dependent variable BMI $\left(\mathrm{kg} / \mathrm{m}^{2}\right), \mathrm{R}=0.23, \mathrm{R}^{2}=0.05, \mathrm{~F}(1,15)=7.93, \mathrm{p}<0.005$} \\
\hline & Beta & SE & $B$ & SE & $t(148)$ & p-level \\
\hline Intercept & & & 112.20 & 4.35 & 25.78 & $<0.0001$ \\
\hline Food psychological reactance & 0.23 & 0.08 & 1.10 & 0.391 & 2.82 & $=0.006$ \\
\hline
\end{tabular}

$\%$ BF-BI (UB) = percentage of body fat mass (upper body) measured by bioelectrical impedance technique; \% $\mathrm{BF}-\mathrm{BI}(\mathrm{LB})$ = percentage of body fat mass (lower body) measured by bioelectrical impedance technique; $\mathrm{BMI}=$ Body Mass Index; $\mathrm{SE}=$ standard error .

the term of FC behavior. However, the high prevalence of FC behavior found in the present study is similar to that reported for many investigators around the world [8] [15] [25]. One example is the study by Weingarten \& Elston, these investigators evaluated 1000 college students, through a questionnaire regarding 
FC behavior. The researchers showed that $97 \%$ of women experienced this behavior [25]. In the study conducted by Osman in a sample of university students, 91\% of American women and 90\% of Spanish females presented FC behavior [8]. The prevalence of FC behavior in North America reported by Yanovski in 2003 was $97 \%$ [15].

Analyzing the results of the various studies around the world, we observed a broad prevalence of FC behavior. [8] [9] [10] We believed that differences could be due the diversity of instruments used to evaluate the FC behavior, different criteria to study the FC behavior, various sample sizes and the eligibility criteria for selecting the sample of women studied [8] [9] [10] [15]. We also believe that one of the reasons for these discrepancies are differences in the lexicalization, conceptualization and methodologies defined in the study of FC behavior. In our study, we avoided many of these problems. We utilized a valid and reliable instrument for measuring the FC behavior. The questionnaire used in this study was validated according to the socio-cultural characteristics of the study population accounting for biological factors associated with FC behavior, and the women's affective states, like anxiety-symptoms, stress, depression, anger, leisure and food psychological-reactance.

\subsection{Food Craving a Frequent Problem in Women}

The FC behavior is a phenomenon that occurs more often in women. Results of Osman's study showed the prevalence of FC behavior was greater in women than in men [8]. Weingarten \& Elton's study reported the prevalence of FC behavior was $29 \%$ higher in females compared to males [25]. The results of several studies worldwide have shown that women are more likely to have FC behavior related to female's affective states triggering FC behavior. Researchers from several countries demonstrated that women have eating-disorder symptoms associated with anxiety, stress, depression, changes in the behavior, and low self-esteem; the latter three times less common in males than in females [7] [8] [9] [10].

\subsection{Food Craving, BMI and Body Composition}

In this investigation, we stratified women according to their BMI and compared the frequencies of FC behavior among females with low-, normal-, and overweight, and obese; the results were $4 \%, 60 \%, 29 \%$, and $7 \%$, respectively. In this investigation, we found that women with normal weight had higher frequency of FC behavior. This result could be explained because women have more stress, and anxiety to maintain their normal body weight, in a demanding society to give greatest value to the thinness and lean physical appearance [1] [4]. We also demonstrated that: 1) the prevalence of mild intensity FC behavior in the volunteers was more frequently observed among women of normal weight (54\%); 2) the prevalence of FC behavior of moderate intensity was presented more in women who are overweight (7\%); and 3) severe FC behavior, were reported in only $0.7 \%$ of women. However, when we compare the median scores of FC be- 
havior of the women stratified according to their BMI, those with the highest BMI had the highest scores of FC behavior. The results of multiple regression tests enable us to predict with $95 \%$ of probability that a woman from the general population with the characteristics of the study sample, will exhibit greater intensity of the food craving behavior as their body mass index and body fat increase. However, one limitation of this research is that the number of women with obesity and morbid obesity was very small. This because the vast majority of obese and morbidly obese women did not want to participate in the study (they did not accept that investigators would measure their weight or their body fat).

The results obtained in this investigation are consistent with reports of other investigators, who point out that the FC behavior is associated with eating problems behavior, body weight and BMI [7] [25]. However, some investigators did not find significant relationship between the FC behavior and BMI [10] [12] [16]. Another important aspect in the increase in body weight is that obese individuals with a higher score of FC behavior select foods with high-energy content. Therefore, the body composition of a person is important to consider in the study of FC behavior. An individual may have a higher BMI categorizing them as obese but their body-composition suggests they have a high lean body mass. In the present study, we found that individuals with high body fat had higher scores of FC behavior $(\mathrm{p}<0.05)$.

\subsection{Food Craving Behavior and Menstrual Cycle}

Mood changes are frequent during the menstrual cycle and primarily occur during the premenstrual period [26]. In 2007, Hill demonstrated that mood changes trigger FC behavior [3]. The mood changes that trigger FC behavior could be generated, by multiple factors among which are variations in the levels of sex hormones during the menstrual cycle [26]. In a previous study, we demonstrated that leptin serum levels changes during the menstrual cycle in normal weight subjects; however, in obese females there were not changes in this protein serum level [27].

In the follicular phase of the menstrual cycle (days $1-14$ from menstrual bleeding), an elevation of serum estrogen levels is associated with an increase of serotonin levels and improved mood. During the luteal phase of the menstrual cycle (15 - 28 days from the start of menstrual bleeding), there is an increase in the levels of progesterone up to $1-3$ days before menstruation. Progesterone is a hormone that has anxiolytic properties [13] [14] [27]. In a previous study, we reported that during the luteal phase $30 \%$ to $35 \%$ of young women experienced symptoms of sadness, depression, anxiety and fatigue [13]. Therefore, fluctuations in the mood of women would be expected in the luteal phase of the menstrual cycle leading to emotional situations, which generate FC behaviors. In 2003, Cepeda-Benito and co-workers [2] demonstrated that $32 \%$ of the women perceived their desire to ingest food was related with the emotional changes during the menstrual cycle. Nevertheless, the results obtained in our present 
study showed no significant differences in scores of FC behavior of women who were in the follicular and luteal phases of the menstrual cycle $(p>0.05)$.

\subsection{Affective States of Women and Food Craving Behavior}

In our present investigation, study volunteers were classified per FC behavior triggers: leisure, anxiety/stress, depression, anger, and food psychological reactance. We found that $96 \%$ of the women studied reported leisure as their FC trigger. It followed in similar frequencies for food psychological-reactance, depression and anxiety/stress, and anger (highest to lowest, respectively). Women reported FC behavior during periods of leisure and rest. These feelings occurred when subjects were not at work, feeling bored, or at a social event where there is availability of food. However, the multiple regression analysis demonstrated food psychological reactance was a significant predictor of BMI and body fat mass (Table 4). Psychological reactance is caused by food restriction or a lowcalorie eating plan or diet that limits the freedom to choose the food to be ingested; it consequently produces an increased desire to consume food. These diets cause feelings of physiological and psychological deprivation triggering FC behavior [1] [4]. Food is used as a means of distraction and alleviation of these negative moods causing FC behavior [1] [2] [4].

\section{Conclusion}

High frequency of the FC behavior found in this sample of reproductive age woman who lived in the urban areas of Leon, Guanajuato, Mexico was similar to that presented at the worldwide level. Women with higher score of food craving behavior and food psychological reactance (FPR) have higher BMI and higher body fat mass, compared with female with lower scores of FC behavior and FPR. The FC behavior is generated primarily by leisure, and negative moods such as food psychological reactance, followed by depression (sadness), anxiety/stress, and less frequently anger. Therefore, the study of FC behavior may be the key to identify possible eating behaviors that lead to increased weight and body fat or failing in eating behavior disorders. It is noteworthy that the phases of the menstrual cycle were not associated with the FC behavior. However, this study has limitations because most of the participants were non-obese women.

\section{Acknowledgements}

Tonatiuh Garcia Campos, chair of the Division of Health Sciences of the Campus Leon, University of Guanajuato, Mexico; for his recommendations and guidance in the validation of the Food Craving behavior questionnaire. The authors also want to acknowledgments to all the volunteers who participate in this study.

\section{Funding}

This research did not receive any specific grant from funding agencies in the public, commercial, or not-for-profit sectors. 


\section{Conflict-of-Interest Statement}

Authors declare no conflict of interests for this article.

\section{References}

[1] Rodríguez, S, Mata, J.L. and Moreno, S. (2007) Psychophysiology of Food Craving and Bulimia Nervosa. Clinical and Health, 18, 99-118.

http://www.redalyc.org/articulo.oa?id=180613874007

[2] Cepeda-Benito, A, Fernandez, M.C. and Moreno, S. (2003) Relationship of Gender and Eating Disorder Symptoms to Reported Cravings for Food: Construct Validation of State and Trait Craving Questionnaires in Spanish. Appetite, 40, 47-54. https://doi.org/10.1016/S0195-6663(02)00145-9

[3] Hill, A.J. (2007) Symposium on Molecular Mechanisms and Psychology of Food Intake the Psychology of Food Craving. Proceedings of the Nutrition Society, 66, 277-285. https://doi.org/10.1017/S0029665107005502

[4] Rodriguez, S., Mata, J.L., Moreno, S., Fernandez, M.C. and Vila, J. (2007) Psychophysiological Mechanisms Involved in Affective Regulation and Food Restriction of Women at Risk of Bulimia Nervosa. Psicothema, 19, 30-36.

[5] Corby, K.M., O’Neil, P.M. and Pawlow, L. (2006) Changes in Food Cravings during Low-Calorie and Very-Low-Calorie Diets. Obesity, 14, 115-121. https://doi.org/10.1038/oby.2006.14

[6] Vecina-Jimenez, M.L. (2006) Positive Emotions. Psychologist Papers, 27, 9-17.

[7] Gendall, K.A., Joyce, P.R. and Sullivan, P.F. (1997) Impact of Definition on Prevalence of Food Cravings in a Random Sample of Young Women. Appetite, 28, 63-72. https://doi.org/10.1006/appe.1996.0060

[8] Osman, J.L. and Sobal, J. (2006) Chocolate Cravings in American and Spanish Individuals: Biological and Cultural Influences. Appetite, 47, 290-301. https://doi.org/10.1016/j.appet.2006.04.008

[9] Hill, A.J. and Heaton-Brown, L. (1994) The Experience of Food Craving: A Prospective Investigation in Healthy Women. Journal of Psychosomatic Research, 38, 801-814. https://doi.org/10.1016/0022-3999(94)90068-X

[10] Hill, A.J., Weaver, C.F. and Blundell, J. (1991) Food Craving, Dietary Restraint and Mood. Appetite, 17, 187-197. https://doi.org/10.1016/0195-6663(91)90021-I

[11] Pelchat, M.L. (1997) Food Cravings in Young and Elderly Adults. Appetite, 28, 103-113. https://doi.org/10.1006/appe.1996.0063

[12] Lafay, L., Thomas, F., Mennen, L., Charles, M.A., Borys, J.M. and Basdevant, A. (2001) Fleurbaix Laventie Ville Santé Study Gender Differences in the Relation between Food Cravings and Mood in an Adult Community: Results from the Fleurbaix Laventie Ville Santé Study. International Journal Eating Disorders, 29, 195-204. https://doi.org/10.1002/1098-108X(200103)29:2<195::AID-EAT1009>3.0.CO;2-N

[13] Huerta-Franco, M.R. and Malacara, J.M. (1993) Association of Physical and Emotional Symptoms with the Menstrual Cycle and Life-Style. The Journal of Reproductive Medicine, 38, 448-454.

[14] Huerta, R. (2000) The Mood of the Woman during Her Reproductive Cycle. Mental Health, 23, 52-60. www.redalyc.org/pdf/582/58232307.pdf

[15] Yanovski, S. (2003) Sugar and Fat: Cravings and Aversions. The Journal of Nutrition, 133, 835S-837S.

[16] Fedoroff, I.D.C., Polivy, J. and Herman, C.P. (1997) The Effect of Pre-Exposure to Food Cues on the Eating Behavior of Restrained and Unrestrained Eaters. Appetite, 
28, 33-47. https://doi.org/10.1006/appe.1996.0057

[17] Angell, M. (2000) Investigators' Responsibilities for Human Subjects in Developing Countries. New England Journal of Medicine, 342, 967-969. https://doi.org/10.1056/NEJM200003303421309

[18] Zimmermann, U., Kraus, T., Himmerich, H., Schuld, A. and Pollmächer, T. (2003) Epidemiology, Implications and Mechanisms Underlying Drug-Induced Weight Gain in Psychiatric Patients. Journal of Psychiatric Research, 37, 193-220. https://doi.org/10.1016/S0022-3956(03)00018-9

[19] Bronfman, M., Castro, V., Guiscafré, H., Castro, R. and Gutiérrez G. (1998) The Measurement of Inequality: A Methodological Strategy. Analysis of the Socioeconomic Characteristics of the Sample. Archives of Medical Research, 19, 351-360. http://www.scielo.br/scielo.php?script $=$ sci nlinks\&ref $=000094 \& p i d=S 1413-8123200$ 300010000500014\&lng=en

[20] Reyes-Lagunes, I. (1993) Natural Semantic Networks, Their Conceptualization and Their Use in the Construction of Instruments. Mexican Journal of Psychology and Personality, 9, 81-97. http://www.redalyc.org/pdf/461/46110301.pdf

[21] Haskell, W.L., Lee, I.-M., Russell, R.P., Pate, R.R., Powell, K.E., Blair, S.N., Franklin, B.A. and Bauman, A. (2007) Physical Activity and Public Health. Updated Recommendation for Adults from the American College of Sports Medicine and the American Heart Association. Circulation, 116, 1081-1093. https://doi.org/10.1161/CIRCULATIONAHA.107.185649

[22] Nevill, A.M., Stewart, A.D., Olds, T. and Holder R. (2004) Are Adult Physiques Geometrically Similar? The Dangers of Allometric Scaling Using Body Mass Power Laws. American Journal of Physical Anthropology, 124, 177-182. https://doi.org/10.1002/ajpa.10351

[23] Azad, A. and Zamani, A. (2014) Lean Body Mass Can Predict Lung Function in Underweight and Normal Weight Sedentary Female Young Adults. Tanaffos, 13, 20- 26.

[24] World Health Organization (1995) Physical Status: The Use and Interpretation of Anthropometry. Report of a WHO Expert Committee. World Health Organization Technical Report Series, 854, 1-452.

[25] Weingarten, H.P. and Elston, D. (1991) Food Craving in a College Population. Appetite, 17, 167-175. https://doi.org/10.1016/0195-6663(91)90019-0

[26] Freeman, E.W. (2003) Premenstrual Syndrome and Premenstrual Dysphoric Disorder: Definitions and Diagnosis. Psychoneuroendocrinology, 28, 25-37. https://doi.org/10.1016/S0306-4530(03)00099-4

[27] Huerta-Franco, M.R., Huerta-Franco, E.R. and Vargas-Luna, F.M. (2014) Differential Expression of Leptin and Leptin Receptor mRNA in Obese and Non-Obese Women across the Menstrual Cycle. Food and Nutrition Sciences, 5, 2265-2273. http://www.scirp.org/journal/fns https://doi.org/10.4236/fns.2014.522240 
Submit or recommend next manuscript to SCIRP and we will provide best service for you:

Accepting pre-submission inquiries through Email, Facebook, LinkedIn, Twitter, etc. A wide selection of journals (inclusive of 9 subjects, more than 200 journals)

Providing 24-hour high-quality service

User-friendly online submission system

Fair and swift peer-review system

Efficient typesetting and proofreading procedure

Display of the result of downloads and visits, as well as the number of cited articles Maximum dissemination of your research work

Submit your manuscript at: http://papersubmission.scirp.org/

Or contact fns@scirp.org 